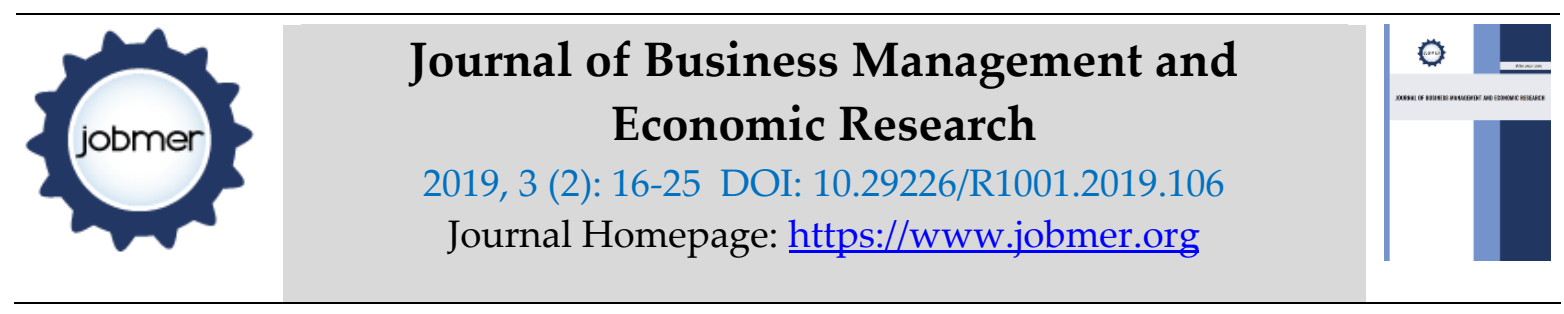

\title{
Strategies For Developing High Performing Work Teams (HPWTS) In Modern Organizations
}

\section{Peter Terna Iorhen}

The Administrative Staff College of Nigeria (ASCON)

Topo-Badagry, Lagos State,Nigeria

ternaiorhen@yahoo.com

\begin{abstract}
This paper is aimed at discussing strategies for developing High Performing Work Teams (HPWTs) in modern organizations. As organizations are moving from individualistic based-operations to collective basedoperations, work teams are required to synergize with identical focus to pursue common goals. The consistency in pursuing these goals require work teams with high performing qualities like consistent commitments and accomplishments, effective communication, relevant and multiple skills, high level of accountability and effective leadership among others. The paper deployed qualitative methodology with the use of secondary materials. The paper covered definition and explanation of concepts, characteristics of high performing work teams, types of teams, relevance of high performing work teams, phases for developing work teams and principles for developing high performing work teams. The paper concluded that to nurture work teams for high performance, modern organizations are expected to ensure that their work teams are taken through all the phases of team development without ignoring the principles of developing work teams.
\end{abstract}

Key Words: Strategies, development, High Performance Work Teams, modern organizations 


\section{Introduction}

Organizations today are beginning to see the importance of pooling employees together with identical focus for a common goal. The idea behind this fact is that, employees without identical focus can hardly achieve commonality and once the cohesion is not exhibited, the consequence is that the organizational performance will be affected negatively. It is the synergy among employees that results to effective work teams with innovative and creative ideas to fashion out quality products and deliver effective services. No wonder, teams have become an essential part of work in organizations like Honeywell, General Electric, Australian Airlines, Honda and Toyota automobile and Telecommunication Corporations among others. In fact, about $80 \%$ of all fortune companies are using teams in almost all parts of their organizations (Robbins and DeCenzo, 2008: 246). As organizations have restructured themselves to compete more effectively and efficiently, they have turned to teams as a better way to use employees' talents. Teams are more flexible and responsive to changing events than traditional departments or other forms of permanent groupings (Robbins, Judge and Vohra, 2013:328).

The complexity of organizations and quest to continuously improve operations in order to meet customers' demands, improve quality and productivity, create job satisfaction and improve profit for survival and sustainability require work teams that are high performing. High performing work teams are characterized by clear goals, unified commitment, good communication, mutual trust, effective leadership, external and internal support, negotiating skills and relevant skills (Robbins and DeCenzo, 2008: 251). In addition, HPWTs are known for consistent accomplishments, consistent problem solving, high complimentary skills, high trust, creativity and rapid decisions. These attributes are known to be the hallmark of high performing work teams in modern organizations. It is important to note that it is by synchronizing the above mentioned attributes that work teams become effective and high performing. It is expected that employees of high performing organizations share in common the attributes of high performing teams so as to roll in the same direction to dominate any industry, in any market, against any competition, at any time. Therefore, as modern organizations put teams in place for continuous improvement and competitive advantage, the challenge still remains developing such teams for effectiveness and high performance. It is in this connection that this paper deployed qualitative methodology using secondary sources to discuss in details the strategies required in developing teams that are high performing and effective in modern organizations. The paper is fashioned to cover definition and explanation of concepts, characteristics of high performing work teams, types of teams, relevance of high performing work teams, phases for developing work teams and principles for developing high performing work teams.

\section{Definition and Explanation of Concepts}

In discussing this paper, key concepts will be defined and explained to facilitate our understanding.

\subsection{Work Teams and Work Groups}

The two concepts are used interchangeably, but they are not the same and also distinct in nature. Scholars have perceived and interpreted these concepts in diverse ways. Scholtes (1988:3) defined a team as a group of people pooling their skills, talents and knowledge. Katzenbach and Smith (1993:45) add the elements of commitment and mutual accountability, defining a team as a 
small number of people with complimentary skills who are committed to a common purpose, performance goals and approach for which they hold themselves mutually accountable. According to Forsyth (2010) cited in Zoltan and Vancea(2015:96), teams are structured groups of people working on the basis of well-defined common goals that require coordinated interactions in order to perform certain tasks. This definition highlights one of the key features of team, that is, its members work together on a common project for the achievement of which they are all accountable. From the two definitions, a team can be seen as a group of persons working together with complimentary skills and experiences for a common goal. The concept of work team is more common in business and seen as integral unit of the organization functioning and the interest for it has increased in recent time, as many organizations turn to the organization of work in teams, yet they are seen as solutions to organizational problems, including those related to productivity (Zoltan, Bordeianu \& Vancea, 2013) cited in Zoltan and Vancea(2015:96). Work teams are individuals who come together to generate positive synergy through a coordinated effort where individual efforts result in a level of performance that is greater than the sum of those individual inputs (Robbins and DeCenzo, 2008: 248). Work teams are characterized by common goals, shared responsibilities, unified commitment, complementary skills, mutual trust and interdependence among others.

On the other hand, work group is a collection of peoples who work in the same area or have been drawn together to undertake a task but do not necessarily come together as a unit and achieve significant performance improvement (Bateman and Snell, 2002: 441). Work groups are individuals who come together with the aim to share information and make decisions to help each member perform within his or her area of responsibility. Work groups have no need or opportunity to engage in collective work that requires joint effort. So their performance is merely the summation of each group member's individual contribution. There is no positive synergy that would create an overall level of performance greater than the sum of the inputs (Robbins et al, 2013: 329). Katzenbach and Smith (1993:45) said a work group constitutes members that perform their tasks successfully and achieve personal satisfaction, but not necessarily share the same objectives, with poor coordination. Work groups are characterized by individual efforts, lack of mutual trust, individual accountability and lack of common goal among others.

\subsection{High Performing Work Teams (HPWTs)}

High performing team is a group of people who share a common vision, goals, metrics and who collaborate, challenge and hold each other accountable to achieve outstanding results. Members of high performing team have a clear and vision of where they are headed and what they want to accomplish, are excited about that vision they took part in creating, act from clearly defined priorities to achieve their vision, have clear measures of success and receive feedback about how they're doing, maintain open communication and positive relationships with each other, identify and solve problems, make decisions when and where they occur, successfully manage conflict, share leadership responsibilities, participate in productive meetings, have clearly defined roles and work procedures and cooperate cross-functionally. (www.centerod.com/docs/CenterOD DevelopHighPerformanceTeams.pdf).

HPWTs are teams that consistently develop goals and plans, enhance communication among members, develop and maintain positive relationships among members, solve problems 
and make decisions on a timely basis, successfully manage conflict, facilitate productive meetings, clarify roles for team members, operate in a productive manner, exhibit effective team leadership and provide development opportunities for team members (www.goiam.org/images/articles/headquarters/departments/hpwopartnerships/ten characteristics hpwteam.pdf). HPWTs are teams that are optimum in goal setting, communication, complimentary skills, accountability and leadership among others. Such teams deliver results and receive recognition and on the basis of trust, team members accelerate their personal and collective learning (Eigenhuis and Dijk, 2008:135). HPWTs are teams with performance norms, that is shared beliefs about how people should think and behave. Members of HPWTs are expected to be focus, committed and hard working, eager to solve problems and willing to support one another.

The distinction between high performing work teams and natural work teams is that, HPWTs have the ability to perform at optimum level for a long period of time and to accomplish its work in efficient and effective manner while natural work teams have the ability to perform but not at optimum level and lacks consistency in accomplishment.

\subsection{Characteristics of High Performing Work Teams}

These are inherent attributes and features exhibited by work teams that seem to be optimum. Scholars in their research identify these characteristics distinctively. According to Lewis, Goodman and Fandt (2004:440), high performing teams have mutual influence, common purpose, interaction and interdependence relationship as their attributes. Innovative ideas, goal accomplishment and adaptability are also features (Certo, 2000:391). Eigenhuis and Dijk (2008: 131) said high performing teams make decisions more rapidly, create support for their decisions in the wider organization and adapt faster to changing market conditions. Finally, high performing work teams are characterized by clear goals, unified commitment, good communication, mutual trust, effective leadership, external and internal support, negotiating skills and relevant skills (Robbins and DeCenzo, 2008: 251). Major features of high performing work teams are discussed in details below.

Clear understanding of goals and objectives: The goals and objectives to be pursued are not ambiguous to high performing teams. In clear terms, they have a full understanding of these goals and objectives and because of their understanding, they redirect their energy away from personal concerns to specifically actualize team mandate.

High commitment: Team members show and display high level of dedication as they give time and put efforts for the achievement of team goals.

Common goal: The ability to team up for a common purpose is inevitable, because team members know in clear terms what to achieve, therefore, their focus is solely on the result and nothing else.

Relevant skills: Team members have skill sets required at different work process to accomplish diverse assignments for the attainment of the overall goals. Instead of possessing only the technical skills, team members also have the interpersonal kills among others to achieve excellence.

Creative ideas: Team members are innovative in thinking, as they initiate different ways of approaching issues relating team goals. 
Supportive decisions: Team members assist each other to make choices required in pursuing organizational goals and as team members interact freely, the willingness to make inputs to decisions is not compromised

Open communication: There is free flow of information between individuals and organization. This facilitates feedback and guide team members to correct misunderstandings as they arise. Team members relate freely by sharing feelings and ideas.

Effective leadership: Team members motivate themselves in difficult situations, they make clarifications on goals to pursue, adapt to change, help team members realize their potentials and more importantly, they are focus.

Mutual trust: Team members have confidence in themselves and exhibit intense loyalty and dedication to each other. Integrity of team members is of high esteem.

Performance norms: Every member is expected to follow the acceptable pattern and style in pursuing team's goal. There are laydown rules for members to follow, so as to guide team's operations.

\subsection{Types of Teams}

Work teams in organizations today can be categorized on the basis of objective, function and scope among others. According to Certo(2000:387) three types of teams are commonly found in today's organizations namely; problem solving teams, self-managed teams and cross-functional teams. Robbins and DeCenzo (2008: 248) stated that the four most common forms of teams in organizations are functional teams, problem-solving teams, self-managed teams and crossfunctional teams. Robbins et al (2013: 330) mentioned problem -solving teams, self-managed teams, cross-functional teams and virtual teams as the most common teams in an organization. Torrington et al (2002) cited in Suff and Reilly (2006:4) identified four broad teams; production and service teams, cross- functional management teams, functional teams and problem-solving teams.

In this paper, problem-solving teams, functional teams, self-managed teams, crossfunctional teams and virtual teams will be discussed.

Problem-solving teams: A number of employees set up by the organization to share ideas and discuss ways of improving work processes and methods. These teams assist the organization in offering solutions to operational challenges.

Functional teams: Managers in various departments, sections and units including employees under them who put efforts together to improve work activities and also solve specific problems affecting a particular department, section or unit.

Self-managed teams: A number of employees constituted by the organization to plan, organize and control and complete work processes without much management interference. They take responsibility of the entire work process from the starting point to the finishing point with minimal directives from the management.

Cross-functional teams: Employees of almost the same level from different departments, sections or units within the organization brought together due to its expertise to coordinate 
activities of different departments, sections and units for the accomplishment of organizational task.

Virtual teams: Team members situated in different geographical areas who are linked by modern communication technology like wide-area networks, videoconferencing and e-mail to solve problems and also discuss issues affecting the organization.

\subsection{Relevance of High Performing Work Teams}

HPWTs contribute significantly to organizations as well as individuals. According to Suff and Reilly (2006:39) organizations tend to benefits from improvements in productivity, quality, customer satisfaction levels, employee commitment while team members tend to enjoy great job satisfaction from freedom, responsibility and flexibility of working in groups. Both organizational and individual benefits are clearly discussed below.

\section{Organizational Benefits:}

High productivity: Employees put in their best as a result of the cohesive environment and coupled with the friendly and conducive atmosphere, there is very tremendous output.

High quality: The freedom and cohesiveness among employees, give room to generate ideas for continuous improvement in organizational product and services.

High level of customer satisfaction: The high quality of goods and services produced and provided as a result of continuous improvements from new ideas, meet customers' satisfaction and retain them.

Competitive edge: Organizations with high performing work teams have competitive advantage over organizations that have work teams that are not effective and high performing.

Improved profitability: As organizations meet customers' satisfaction with products and services that of high quality, the sales is on the rise and the organizational turnover improves.

\section{Individual Benefits:}

Job satisfaction: With the friendly and cohesive environment, employees in the organization are happy doing their jobs because there is no fear and nothing to worry about.

Freedom: As employees interact and share ideas in the course of working for team goals, they become free among themselves and are willing to open up for more information.

Interpersonal skills: The interaction among employees enables them to sharpen their interpersonal skills and develop good work relationship.

Experience: As employees work together continuously, they are exposed to new ideas that equip them to develop in their careers.

\subsection{Phases for Developing Work Teams}

Work teams go through phases and stages before they become effective and high performing. Within this period, team members exhibit different behaviours, attitudes and characteristics. The time require for each of the stages vary greatly, with each stage lasting until its paramount issues are resolved. These stages are interdependent, because is only when issues at a 
particular stage are clarified before members move unto another stage. It is in this connection that Lewis et al (2004: 446) said the process of development is ongoing and complex and therefore, new groups may progress through these stages, but if the group's membership changes, the group may regress to an earlier stage, at least temporarily. Research has indicated that teams that proceed through the developmental stages successfully seem to outperform and sustain higher levels of performance when compared to teams that do not (Bushe \& Coetzer, 2007) cited in Lunenburg and Lunenburg (2015:4).

In developing work teams to high performing teams, Bruce Tuckman in 1965 developed four major stages; forming, storming, norming and performing. Eigenhuis and Dijk (2008: 131) extended these stages to five by adding high performing while Lewis et al (2008: 448) and Certo(2000: 391) included adjourning to the first four stages developed by Tuckman. The understanding of these stages is of great importance to any organization that will decide to develop its work teams.

Forming stage: This is a stage where individuals come together and begin to think of themselves as members of a team. This is a period of uncertainty, stress and anxiety. As individual members explore to know what is expected of them, what kind of people constitute the team and the skills team members possess. This is an exploratory period where team members search for information to organize their activities. The behaviours most common for individuals in the forming stage include dependency, keeping feelings to themselves, experiencing confusion and uncertainty about what is expected, being polite, showing hesitancy about how to proceed, etc. Teams in forming stage should be given enough time to get familiar with each other before attempting to carryout their responsibilities.

Storming stage: The emergence of conflict and disagreement among members indicates the beginning of storming stage. As individual members argue about roles and procedures, there is no more unity and they become uncomfortable interacting with one another. Competition for the leadership role and conflict over goals are dominant themes at this stage. Some members withdraw or try to isolate from the tension generated. The behaviours most common for individuals in the forming stage include arguments, pride, power struggle, withdrawal, conflict, etc. Team members should be given free hand to clarify issues and how they intend going about their goals and objectives.

Norming stage: After the conflict stage, norming begins. The norming stage of development is a stage in which team members come to agree among themselves on roles, goals, rules and acceptable behaviour while working on the team. It is a stage of team development where a real sense of cohesion and belonging begins to emerge. The behaviours most common for individuals in the norming stage include sense of cohesion, sense of success, sharing of feelings and effective feedback. Team members should develop acceptable norms and values that will be instrumental in building a successful organization.

Performing stage: At this stage, team members channel their efforts in carrying out tasks, as they get to understand and work well with everyone on the team. It is a stage where team members become productive as they work towards accomplishing organizational goals. Team members are fully focused on solving complex problems and meeting assigned challenges. The behaviours most common for individuals in the performing stage include commitment to 
challenges, problem solving, commitment to task and high level of interdependence. The accomplishments of team members should be recognized regularly and rewards must also be assigned to get the best from team members.

Adjourning stage: This is the last stage in team development where there is termination of task and disengagement from relationship-oriented behaviours. At this stage, the team finishes its job and prepares to disband. The behaviours most common in this stage include disappointment for loss of work and personal relationships among team members. Team members should be briefed before the termination of task, to avoid them from psychological trauma.

\subsection{Principles for Developing High Performing Work Teams}

Modern organizations can nurture its work teams for high performance by ensuring that work teams meet up with the required principles such as team size, team composition, organizational support, clear and challenging goals performance norms, feedback mechanism, team training, team trust, team accountability, team leadership, etc.

Team size: The task and assignment should determine the number of persons that will make up a work team, but the ideal size for a work team is six to seven persons. It should be noted that if the team is too large, social loafing will be encouraged and most members will end up not contributing to the goals of the team and if the team is too small, the required skills will be lacking to pursue team goals.

Team composition: It is important to ensure that team members have complimentary competencies to enable them solve problems that will arise in the course of team's operations and activities. Finally, there should be gender balancing among team members.

Organizational support: Moral and material support should be given to team members so as to empower them make decisions within an agreed framework and mandate for the team. And there should be availability of appropriate information systems and a stimulating physical working environment.

Clear and challenging goals: Well defined goals that require complimentary skills and critical thinking to actualize should be set for team members to pursue.

Performance norms: The laydown rules, pattern of behaviour and work style expected of team members should be stated in clear terms so as to guide their conduct in pursuing team's goal.

Feedback mechanism: In order to have a report on the performance of each team member, a feedback system is required. This system enables team members to adjust if their performance is below standard.

Team training: Organizations are expected to expose team members to relevant training programmes to enable them acquire interpersonal, problem-solving and decision making skills that will facilitate their team operation and cohesion.

Team trust: Ensuring that team members develop confidence and integrity for each other in carrying out team's task.

Team accountability: Team members are expected to take responsibilities assigned by their organizations and ensure that each of the responsibilities is being accounted for. 
Team leadership: The essence of team leadership is to stimulate, motivates and inspire other team members to strive in difficult situations to actualize team's goal. Most importantly, team leadership enables team members to be visionary and focus in pursuing team's goal.

\section{Conclusion}

Organizations are now shifting from individualistic to collective efforts with work teams that are synergizing to pursue common goals. The consistency in pursuing and accomplishing these goals require work teams that are effective and high performing, members of such work teams are characterized with relevant and multiple skills, positive relationships, high level of accountability and integrity, etc. Therefore, for work teams to be nurtured for high performance, modern organizations are expected to ensure that these work teams are taken through all the phases of team development without neglecting the principles required for developing high performing work teams.

\section{References}

Bateman, T.S and Snell,S.A.(2002). Management: Competing in the New Era. (5 $5^{\text {th }}$ edition). New York: McGraw-Hill.

Certo, S.C.(2000). Modern Management. (8th edition). New Jersey: Prentice Hall.

Eigenhuis, A and Dijk, R.V.(2008). HR Strategy for the High Performing Business: Inspiring Success through Effective Human Resource Management. (2nd edition). United Kingdom: Kogan Page.

Katzenbach, J., and Smith, D., (1993). The Wisdom of Teams: Creating the High-Performance Organization. Cambridge, MA. Harvard Business School Press.

Lewis, P. S., Goodman, S. H., and Fandt, P.M.(2004). Management: Challenges for Tomorrow's Leaders. (4 $4^{\text {th }}$ edition). Canada: Thomson.

Lunenburg, F. C and Lunenburg, M. R(2015). Developing High Performance Teams: LongStanding Principles That Work. International Journal of Organizational Behavior in Education Volume 3, number1.

Robbins, S.T and DeCenzo,D.A(2008). Fundamentals of Management: Essential Concepts and Applications. (6 $6^{\text {th }}$ edition). Upper Saddle River: Pearson Prentice Hall.

Robbins,S.T, Judge, T. A, Vohra,N (2013). Organizational Behaviour. (5 $5^{\text {th }}$ edition). United States: Pearson. 
Scholtes, Peter, 1988. The Team Handbook: How to Use Teams to Improve Quality. Madison, WI, Joiner Associates.

Suff, P and Reilly, P. (2006). Pulling Together: Getting the Most out of Teams. United Kingdom. Institute for Employment Studies.

Zoltan, R. and Vancea, R. (2015). Organizational Work Groups and Work Teams - Approaches and Differences. Ecoforum. Volume 4, Issue 1 (6).

www.centerod.com/docs/CenterOD DevelopHighPerformanceTeams.pdf

www.goiam.org/images/articles/headquarters/departments/hpwopartnerships/ten characteristics hpwteam.pdf

momentum.com/ downloads/the critical steps to building high performance teams.pdf

www.isixsigma.com/implementation/teams/high-performance-teams-understanding-team-

cohesiveness

www.goiam.org/images/articles/headquarters/departments/hpwo-

partnerships/ten characteristics hpwteam.pdf

$\underline{\text { www.centerod.com/docs/CenterOD DevelopHighPerformanceTeams.pdf }}$

www.rialtoconsultancy.com/pdfs/whitepapers/How $\% 20$ to $\% 20$ Create $\% 20 \mathrm{High} \% 20$ Performing $\% 20 \mathrm{~T}$

eams.pdf

www.linkageinc.com/...development.../10-Leadership-Techniques-for-Building-High-...

https://itll.colorado.edu/images/uploads/.../ch06teamwork and working in teams.pdf

https://www.mindtools.com/blog/corporate/wp-content/.../Forming-Storming.pdf

https://salvos.org.au/.../HANDOUT - Tuckmans Team Development Model.pdf

https://www.gla.ac.uk/media/media_358180_en.pdf

https://msu.edu/ morgeson/morgeson_lindoerfer_loring 2010.pdf

www.teamworkandteamplay.com/resources/resource 5stages.pdf

www.naspaa.org/JPAEMessenger/Article/jpae-v16n1/holmes.pdf 